\title{
Cardiac arrest associated with pneumorrhachis and pneumocephalus after epidural analgesia: two case reports
}

\author{
Hyungoo Shin ${ }^{1}$, Hyuk Joong Choi ${ }^{1 *}$, Changsun Kim ${ }^{1}$, Inhye Lee ${ }^{1}$, Jaehoon $\mathrm{Oh}^{2}$ and Byuk Sung Ko ${ }^{2}$
}

\begin{abstract}
Background: Epidural analgesia has become a common procedure to provide excellent pain relief with few complications. Pneumorrhachis and pneumocephalus are rare complications of unintentional dural puncture and injection of air into the subarachnoid or subdural space. No cases of cardiac arrest associated with these complications have been reported in the literature previously.

Case presentation: We report cases of pneumorrhachis and pneumocephalus in two Korean women who previously visited a local pain clinic and underwent epidural analgesia. Thereafter, they were admitted to the emergency department with cardiac arrest. Cardiopulmonary resuscitation was performed on these patients, and return of spontaneous circulation was achieved. The brain and spine computed tomographic scans showed pneumorrhachis and pneumocephalus, respectively. These cases demonstrate that pneumorrhachis and pneumocephalus may occur after epidural analgesia, which may be associated with cardiac arrest in patients.

Conclusions: If cardiac arrest occurs after epidural analgesia, pneumocephalus and pneumorrhachis should be considered as its cause. Although epidural analgesia is a common procedure, caution is warranted during this procedure.
\end{abstract}

Keywords: Pneumorrhachis, Pneumocephalus, Cardiopulmonary resuscitation, Epidural analgesia

\section{Background}

Epidural analgesia is commonly used to provide excellent pain relief with few complications [1]. Although it has become a routine procedure, the complications that are associated with its use may be underestimated [2]. Identification of the epidural space through loss of resistance to air is a widely applied technique during epidural catheter placement [3]. However, several complications are associated with this method, including pneumocephalus [3], subcutaneous emphysema [4], venous air embolism [5], and spinal cord and nerve root compression [6]. Pneumorrhachis and pneumocephalus are rare complications of unintentional dural puncture and air injection into the subarachnoid or subdural space [7]. To the best of our knowledge, no cases of cardiac arrest associated with these complications have

\footnotetext{
* Correspondence: airwaymanage@gmail.com

'Department of Emergency Medicine, College of Medicine, Hanyang

University Guri Hospital, 153 Gyeongchun-ro, Guri-si, Gyeonggi-do 11923,

Republic of Korea

Full list of author information is available at the end of the article
}

been reported. In this report, we describe two cases of cardiac arrest associated with pneumorrhachis and pneumocephalus after epidural analgesia that originated from the use of air during loss-of-resistance placement technique.

\section{Case presentation}

Case 1

Two patients presented to an emergency department (ED) with cardiac arrest (Tables 1 and 2). The first patient was a 78-year-old Korean housewife with a medical history of hypertension. She had no social or environmental risk factors and no family history of cardiac disease. She visited a local pain clinic and underwent epidural analgesia for back pain control 59 min before going to the ED. Her blood pressure decreased as she lost consciousness. Cardiac arrest occurred $20 \mathrm{~min}$ after the procedure. The patient's initial rhythm was asystolic. The emergency medical services team performed cardiopulmonary resuscitation (CPR) on the patient during transport to the hospital. She arrived at the ED with asystole and no measurable vital 
Table 1 Patient characteristics

\begin{tabular}{lll}
\hline & Case 1 & Case 2 \\
\hline Sex & Female & Female \\
Age, years & 78 & 69 \\
Past medical history & Hypertension & None \\
Allergic history & Unknown & Unknown \\
Smoking/alcohol & None & None \\
Injection drug & Triamcinolone $40 \mathrm{mg}$ with lidocaine $60 \mathrm{mg}$ & Triamcinolone 40 mg with lidocaine 60 mg \\
Type of procedure & Epidural analgesia & Epidural analgesia \\
Time interval (min) & & \\
From injection to cardiac arrest & 20 & 35 \\
From cardiac arrest to visiting ED & 39 & 39 \\
CPR duration & 4 & 6 \\
\hline Abbrevation: CPR Cardopula
\end{tabular}

Abbreviations: CPR Cardiopulmonary resuscitation, ED Emergency department

signs. Her Glasgow Coma Scale (GCS) score was 3 points. Her pupils were fully dilated, and all of her brainstem reflexes were lost. Successful return of spontaneous circulation (ROSC) was achieved after $4 \mathrm{~min}$ of CPR. Her blood pressure was 105/33 $\mathrm{mmHg}$, and her heart rate was 79 beats per minute. Spinal computed tomography (CT) performed after ROSC showed air in the spinal canal and prepontine cistern and intradural free air at the C3 level (Fig. 1). The patient was admitted to the intensive care unit (ICU), and post-cardiac arrest care interventions were performed. On the patient's fifth day of hospitalization, she underwent diffusion-weighted magnetic resonance imaging, which showed diffuse signal changes in the bilateral frontotemporoparietal cortex, basal ganglia, and hippocampus, suggesting hypoxic brain injury. Electroencephalography demonstrated diffuse cerebral dysfunction. On the tenth day of hospitalization, she was transferred to a long-term care facility with Cerebral Performance Categories scale (CPC) 4 status. She died 11 days after leaving the hospital.

\section{Case 2}

A 69-year-old Korean housewife presented to the ED with cardiac arrest. She had no past medical, social, or environmental risk factors and no family history of cardiac disease. She visited a local pain clinic and underwent epidural analgesia $74 \mathrm{~min}$ before visiting the ED. She lost consciousness, and cardiac arrest occurred $35 \mathrm{~min}$ after the procedure. She had initial asystole. The emergency medical services team performed CPR and transported her to the ED. She arrived at the ED with asystole and no measurable vital signs. Her GCS score was 3 points. Her pupils were fully dilated, and all brainstem reflexes were lost. Successful ROSC was achieved after $6 \mathrm{~min}$ of CPR. Her blood pressure was $225 / 150 \mathrm{mmHg}$, and her heart rate was 104 beats per minute. Brain CT after ROSC demonstrated extensive anoxic brain damage and pneumocephalus, bilateral middle and lower frontal convexity, and Sylvian fissures (Fig. 2). The patient was admitted to the ICU, and post-cardiac arrest care interventions were performed. Her metabolic acidosis progressed, and she underwent continuous renal replacement therapy for 15 days. Electroencephalography showed diffuse cerebral dysfunction. On the 31st day of hospitalization, she was transferred to a long-term care facility with CPC 4 status. She died 14 days after leaving the hospital.

\section{Discussion and conclusions}

We report two cases of pneumorrhachis and pneumocephalus in patients who previously underwent epidural analgesia. Thereafter, they presented to the ED with cardiac arrest. To the best of our knowledge, no cases of cardiac arrest associated with these complications have been reported previously.

Pneumorrhachis is a phenomenon characterized by intraspinal air mostly due to traumatic and iatrogenic etiologies [8]. Various conditions may cause pneumorrhachis, including iatrogenic manipulations during interventions and lumbar puncture [9]. The diagnostic tool of choice for the detection of pneumorrhachis is CT [10]. Pneumorrhachis is usually asymptomatic and reabsorbs spontaneously and completely the air that passed directly into the blood for several days without recurrence [11]. Therefore, patients with pneumorrhachis are commonly managed conservatively.

The symptoms of pneumocephalus, such as headache, elevated intracranial pressure, vomiting, convulsions, and unstable vital signs, depend on the intracranial air distribution and amount [12]. Less than $2 \mathrm{ml}$ of subarachnoid air can cause headache [13]. However, the air volume that can safely be injected into the epidural space remains to be established [14], and the correlation between the intracranial air amount and headache is unclear [13]. 
Table 2 Laboratory and radiologic findings after return of spontaneous circulation

\begin{tabular}{|c|c|c|}
\hline & Case 1 & Case 2 \\
\hline \multicolumn{3}{|l|}{ ABGA } \\
\hline $\mathrm{pH}$ & 7.18 & 7.05 \\
\hline $\mathrm{pCO}_{2}(\mathrm{mmHg})$ & 55.9 & 51.1 \\
\hline $\mathrm{pO}_{2}(\mathrm{mmHg})$ & 48.2 & 99.2 \\
\hline $\mathrm{HCO}_{3}^{-}(\mathrm{mmol} / \mathrm{L})$ & 21.0 & 14.2 \\
\hline Base excess (mmol/L) & -6.9 & -15.6 \\
\hline Lactate $(\mathrm{mmol} / \mathrm{L})$ & 5.6 & 13.4 \\
\hline $\mathrm{WBC}\left(/ \mathrm{mm}^{3}\right)$ & 8,700 & 15,700 \\
\hline $\mathrm{Hb}(\mathrm{g} / \mathrm{dl})$ & 11.2 & 11.1 \\
\hline Hct (\%) & 34.4 & 35.3 \\
\hline $\operatorname{PLT}\left(/ \mathrm{mm}^{3}\right)$ & 175,000 & 175,000 \\
\hline Serum $\mathrm{Na}^{+} / \mathrm{K}^{+} / \mathrm{Cl} \mathrm{l}^{-}(\mathrm{mEq} / \mathrm{L})$ & 140/4.6/107 & $139 / 3.2 / 106$ \\
\hline Glucose (mg/dl) & 140 & 516 \\
\hline BUN/creatinine $(\mathrm{mg} / \mathrm{dl})$ & 18.1/0.75 & 16.0/0.9 \\
\hline AST/ALT (mg/dl) & $24 / 27$ & $41 / 26$ \\
\hline CRP $(\mathrm{mg} / \mathrm{dl})$ & $<0.3$ & $<0.1$ \\
\hline Cardiac troponin I (ng/ml) & $<0.05$ & $<0.05$ \\
\hline \multirow[t]{3}{*}{ NSE (ng/ml) } & 22.1 (After ROSC) & \multirow[t]{3}{*}{ Not measured } \\
\hline & 59.8 (After $24 \mathrm{~h}$ from ROSC) & \\
\hline & 163.0 (After 48 h from ROSC) & \\
\hline RUA & Nonspecific finding & Nonspecific finding \\
\hline Chest x-ray & $\begin{array}{l}\text { Diffuse bronchovascular bundle thickening } \\
\text { in both lungs }\end{array}$ & Cardiomegaly with pulmonary congestion \\
\hline Electrocardiography & Sinus tachycardia & Sinus tachycardia \\
\hline Echocardiography & No RWMA & No RWMA \\
\hline Brain $\mathrm{CT}$ & Air in the spinal canal and prepontine cistern & $\begin{array}{l}\text { Extensive anoxic brain damage and extensive } \\
\text { pneumocephalus }\end{array}$ \\
\hline Electroencephalography & Diffuse cerebral dysfunction & Diffuse cerebral dysfunction \\
\hline DW-MRI & Hypoxic brain injury & Hypoxic brain injury \\
\hline
\end{tabular}

Abbreviations: $A B G A$ Arterial blood gas analysis, AST Aspartate aminotransferase, ALT Alanine aminotransferase, BUN Blood urea nitrogen, $C T$ Computed tomography, CRP C-reactive protein, DW-MRI Diffusion-weighted magnetic resonance imaging, Hb Hemoglobin, Hct Hematocrit, PLT Platelets, NSE Neuron-specific enolase, ROSC Return of spontaneous circulation, RUA Routine urinalysis, RWMA Regional wall motion abnormality, WBC White blood cell

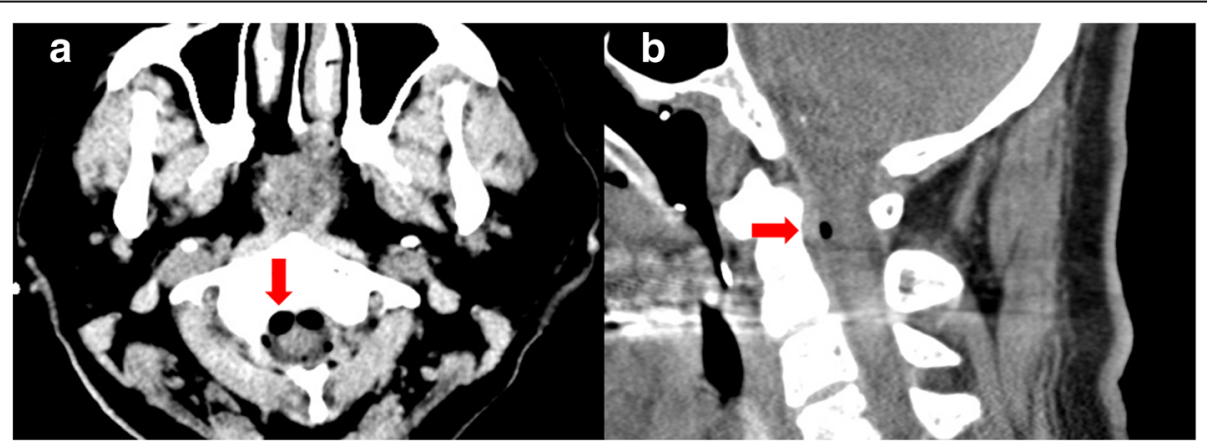

Fig. 1 Brain scan showing air (red arrow) in the spinal canal and prepontine cistern (a). Spinal computed tomographic scan showing intradural free air (red arrow) at the C3 level (b) 


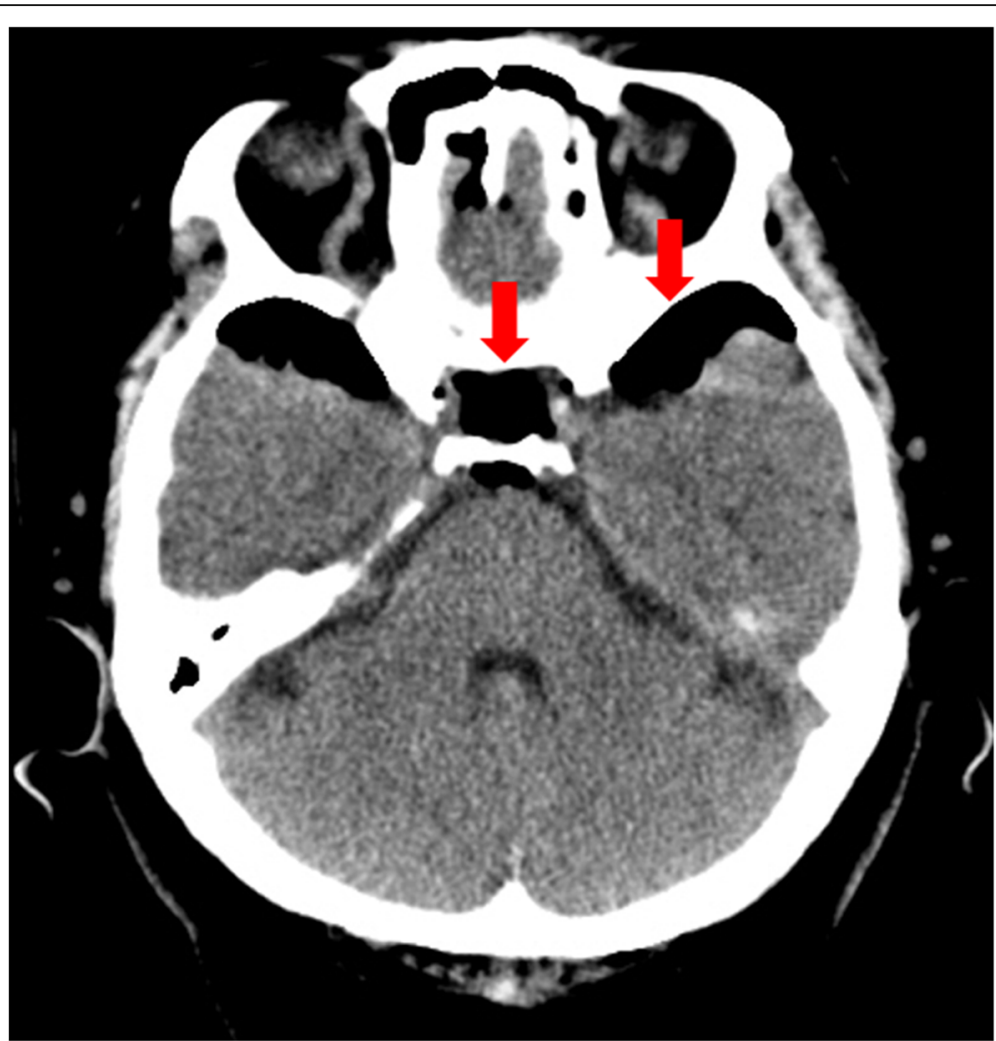

Fig. 2 Brain computed tomographic scan demonstrating extensive anoxic brain damage and extensive pneumocephalus (red arrow), bilateral middle and lower frontal convexity and Sylvian fissures

The entrapped air occupies parts of the cerebrospinal compartment, which may cause both intracranial and intraspinal hypertension and hypotension secondary to either increase or decrease in intracranial and intraspinal pressure [8]. The injected air can also act as a space-occupying lesion and exert pressure on the nervous structures within the spinal canal. Hence, entrapped intraspinal air might cause tension pneumorrhachis and pneumocephalus with nervous tissue compression [15]. These mechanisms may lead to cardiac arrest. Therefore, recognizing the differential diagnosis of altered intraspinal pressure within the cerebrospinal compartment is important to ensuring its adequate management.

There are some limitations to these conclusions. There are other causes of cardiac arrest that were not thoroughly investigated in these cases. Electrocardiograms revealed sinus tachycardia, and the cardiac troponin levels were not elevated in these cases of cardiac arrest. Furthermore, the echocardiograms of the patients displayed no regional wall motion abnormality. However, the exclusion of cardiac causes had not been achieved through coronary angiography. Additionally, anaphylactic shock due to the injected anesthetic drug may have resulted in cardiac arrest. However, we believe that fatal anaphylaxis may be distinguished from pneumorrhachis in that the former can occur within minutes of drug injection compared with the latter. The possibility of total spinal anesthesia following epidural analgesia also needs to be ruled out. Total spinal anesthesia causes sudden physiological changes by blocking the peripheral nerves, including the spinal cord and cranial nerve [16]. Because both patients came from local pain clinics, there was insufficient information to investigate this possibility; including the patients' position, location of injection, type or size of needle, and number of attempts. Thus, it is difficult to further clarify the association between total spinal anesthesia and cardiac arrest. In some case reports, pneumorrhachis or pneumocephalus developed after basic life support, and this possibility cannot be excluded [17].

No empiric treatment guidelines or standards of care exist for pneumorrhachis, owing to its rareness and different pathogenesis and etiologies. Pneumorrhachis is thought to be associated with increased morbidity and mortality [8]. In this report, we present cases of pneumorrhachis and pneumocephalus in two women who presented to the ED with cardiac arrest after epidural analgesia. If cardiac arrest occurs after epidural analgesia, pneumocephalus and pneumorrhachis should be suspected as its cause. The contributing factors for pneumorrhachis and pneumocephalus have to be evaluated, and appropriate interventions should be implemented. Patients with severe and life-threatening conditions 
that can lead to pneumorrhachis and pneumocephalus should be carefully monitored, followed, and considered for admission to an ICU. Care should be taken because patients may have a cardiac arrest after epidural analgesia.

\section{Abbreviations}

ABGA: Arterial blood gas analysis; ALT: Alanine aminotransferase; AST: Aspartate aminotransferase; BUN: Blood urea nitrogen; CPC: Cerebral Performance Categories scale; CPR: Cardiopulmonary resuscitation; CRP: C reactive protein; CT: Computed tomography; DW-MRI: Diffusion-weighted magnetic resonance imaging; ED: Emergency department; GCS: Glasgow Coma Scale; Hb: Hemoglobin; Hct: Hematocrit; ICU: Intensive care unit: MRI: Magnetic resonance imaging; NSE: Neuron-specific enolase; PLT: Platelets; ROSC: Return of spontaneous circulation; RUA: Routine urinalysis; RWMA: Regional wall motion abnormality; WBC: White blood cell

\section{Acknowledgements}

None.

\section{Funding}

None.

\section{Availability of data and materials}

All data generated or analyzed during this study are included in this published article.

\section{Authors' contributions}

$\mathrm{HS}, \mathrm{HJC}, \mathrm{JO}, \mathrm{BSK}, \mathrm{CK}$, and IL performed the investigation. HS performed visualization and wrote the original draft of the manuscript. BSK and $\mathrm{HJC}$ wrote, reviewed, and edited the manuscript. All authors read and approved the final manuscript.

\section{Ethics approval and consent to participate}

The present study protocol was reviewed and approved by the institutional review board of Hanyang University Seoul Hospital (no. 2017-05-028-001).

\section{Consent for publication}

Written informed consent was obtained from the patients for publication of this case report and any accompanying images. A copy of the written consent is available for review by the Editor-in-Chief of this journal. If the consent could not be obtained from the patients, the consent was obtained from the patients' next-of-kin.

\section{Competing interests}

The authors declare that they have no competing interests.

\section{Publisher's Note}

Springer Nature remains neutral with regard to jurisdictional claims in published maps and institutional affiliations.

\section{Author details}

'Department of Emergency Medicine, College of Medicine, Hanyang University Guri Hospital, 153 Gyeongchun-ro, Guri-si, Gyeonggi-do 11923, Republic of Korea. ${ }^{2}$ Department of Emergency Medicine, Hanyang University Seoul Hospital, Seoul, Republic of Korea.

Received: 9 August 2018 Accepted: 29 October 2018

Published online: 22 December 2018

\section{References}

1. Horlocker TT, Wedel DJ. Neurological complications of spinal and epidural anesthesia. Reg Anesth Pain Med. 2000;25:83-98.

2. Singh $\mathrm{S}$, Thakur $\mathrm{H}$. Pneumorrhachis as a result of epidural anesthesia. Acta Anaesthesiol Taiwanica. 2016;54:37.

3. Harrel AE, Draker ME, Massey EW. Pneumocephaly from epidural anesthesia. South Med J. 1983;76:399-400.

4. Prober A, Tverskoy M. Soft tissue emphysema associated with epidural anesthesia. Am J Roentgenol. 1987;149:859-60.

5. Jackson KE, Rauck RL. Suspected venous air embolism during epidural anesthesia. Anesthesiology. 1991;74:190-1.
6. Overdiek N, Grisales DA, Gravenstein D, et al. Subdural air collection: a likely source of radicular pain after lumbar epidural. J Clin Anesth. 2001;13:392-7.

7. Nafiu OO, Urquhart JC. Pneumocephalus with headache complicating labour epidural analgesia: should we still be using air? Int J Obstet Anesth. 2006:15:237-9.

8. Oertel MF, Korinth MC, Reinges MH, et al. Pathogenesis, diagnosis and management of pneumorrhachis. Eur Spine J. 2006;15:636-43.

9. Hirsch M, Katz Y, Sasson A. Spinal cord compression by unusual epidural air accumulation after continuous epidural analgesia. Am J Radiol. 1989;153:887-9.

10. Oertel MF, Korinth MC, Truong HT, et al. Pneumorrhachis. Neuroradiology. 2004:46:171.

11. Aribas OK, Gormus N, Aydogdu Kiresi D. Epidural emphysema associated with primary spontaneous pneumothorax. Eur J Cardiothorac Surg. 2001;20:645-6.

12. Civelek E, Ozcan AR, Aydın A, Erol G, Ebru EE. Complicated pneumocephalus after epidural anesthesia: a case report. Gulhane Med J. 2013:55:132-4.

13. Roderick L, Moore DC, Artru AA. Pneumocephalus with headache during spinal anesthesia. Anesthesiology. 1985;62:690-2.

14. Saberski LR, Kondamuri S, Osinubi OY. Identification of the epidural space: is loss of resistance to air a safe technique? A review of the complications related to the use of air. Reg Anesth. 1997;22:3-15.

15. Hsieh XX, Hsieh SW, Lu CH, et al. A rare case of pneumocephalus and pneumorrhachis after epidural anesthesia. Acta Anaesthesiol Taiwanica. 2015;53:47-9.

16. Woerth SD, Bullard JR, Alpert CC. Total spinal anesthesia, a late complication of epidural anesthesia. Anesthesiology. 1977;47:380-1.

17. Imanishi M, Nishimura A, Tabuse $H$, et al. Intracranial gas on CT after cardiopulmonary resuscitation: 4 cases. Neuroradiology. 1998;40:154-7.

\section{Ready to submit your research? Choose BMC and benefit from:}

- fast, convenient online submission

- thorough peer review by experienced researchers in your field

- rapid publication on acceptance

- support for research data, including large and complex data types

- gold Open Access which fosters wider collaboration and increased citations

- maximum visibility for your research: over $100 \mathrm{M}$ website views per year

At $\mathrm{BMC}$, research is always in progress.

Learn more biomedcentral.com/submissions 